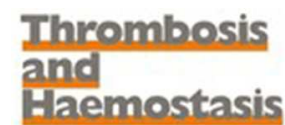

\title{
Potent and specific inhibition of the biological activity of the type-II transmembrane serine protease matriptase by the cyclic microprotein MCoTI-II
}

\begin{tabular}{|r|l|}
\hline Journal: & Thrombosis and Haemostasis \\
\hline Manuscript ID: & TH-13-11-0895.R1 \\
\hline Manuscript Type: & Basic/Clinical Studies: cellular proteolysis and oncology \\
\hline Category: & Basic Science \\
\hline Date Submitted by the Author: & n/a \\
\hline Complete List of Authors: & $\begin{array}{l}\text { Gray, Kelly; University of East Anglia, School of Biological Sciences } \\
\text { Elghadban, Salma; University of East Anglia, School of Biological Sciences } \\
\text { Thongyoo, Panumart; Imperial College London, Department of Chemistry } \\
\text { Owen, Kate; University of East Anglia, School of Biological Sciences } \\
\text { Szabo, Roman; National Institutes of Health, Oral and Pharyngeal Branch } \\
\text { Bugge, Thomas; National Institutes of Health, Oral and Pharyngeal Branch } \\
\text { Tate, Edward; Imperial College London, Department of Chemistry } \\
\text { Leatherbarrow, Robin; Imperial College London, Department of Chemistry } \\
\text { Ellis, Vincent; University of East Anglia, School of Biological Sciences }\end{array}$ \\
\hline \multirow{2}{*}{ Keywords: } & $\begin{array}{l}\text { Proteolysis / pericellular, Proteases, Protease inhibitors, Cell-cell } \\
\text { interactions, Cancer }\end{array}$ \\
\hline
\end{tabular}




\section{Potent and specific inhibition of the biological activity of the type-II transmembrane serine protease matriptase by the cyclic microprotein MCoTI-II}

Kelly Gray ${ }^{\dagger}$, Salma Elghadban ${ }^{\dagger}$, Panumart Thongyoo ${ }^{\ddagger}$, Kate A. Owen ${ }^{\dagger}$, Roman Szabo ${ }^{\text {II }}$,

Thomas H. Bugge ${ }^{\mathbb{I l}}$, Edward. W. Tate ${ }^{\ddagger}$, Robin J. Leatherbarrow ${ }^{\ddagger}$, \& Vincent Ellis ${ }^{\dagger}$

${ }^{\dagger}$ School of Biological Sciences, University of East Anglia, Norwich Research Park, Norwich, NR4 7TJ; United Kingdom; ${ }^{\ddagger}$ Biological and Biophysical Chemistry Section, Department of Chemistry, Imperial College London, United Kingdom; ${ }^{\text {Il }}$ Oral and Pharyngeal Cancer Branch, National Institute of Dental and Craniofacial Research, NIH, Bethesda, MD, USA

\section{Correspondence to:}

Vincent Ellis, PhD

School of Biological Sciences, University of East Anglia, Norwich Research Park, Norwich, NR4 7TJ, United Kingdom Tel.: 44-1603-592570

E-mail: v.ellis@uea.ac.uk

\section{Financial support:}

This study was supported by the Norfolk and Waveney Big C Cancer Charity, the John and Pamela Salter Charitable Trust and by European Union FP6 (Cancerdegradome) project.

Running title: MCoTI-II efficiently inhibits matriptase biological activity 


\section{Summary}

Matriptase is a type-II transmembrane serine protease involved in epithelial homeostasis in both health and disease, and is implicated in the development and progression of a variety of cancers. Matriptase mediates its biological effects both via as yet undefined substrates and pathways, and also by proteolytic cleavage of a variety of well-defined protein substrates, several of which it shares with the closely-related protease hepsin. Development of targeted therapeutic strategies will require discrimination between these proteases. Here we have investigated cyclic microproteins of the squash Momordica cochinchinensis trypsin-inhibitor family (generated by total chemical synthesis) and found MCoTI-II to be a high-affinity $\left(\mathrm{K}_{\mathrm{i}} 9\right.$ $\mathrm{nM}$ ) and highly selective (> 1000-fold) inhibitor of matriptase. MCoTI-II efficiently inhibited the proteolytic activation of pro-hepatocyte growth factor (HGF) by matriptase but not by hepsin, in both purified and cell-based systems, and inhibited HGF-dependent cell scattering. MCoTI-II also selectively inhibited the invasion of matriptase-expressing prostate cancer cells. Using a model of epithelial cell tight junction assembly, we also found that MCoTI-II could effectively inhibit the re-establishment of tight junctions and epithelial barrier function in MDCK-I cells after disruption, consistent with the role of matriptase in regulating epithelial integrity. Surprisingly, MCoTI-II was unable to inhibit matriptase-dependent proteolytic activation of prostasin, a GPI-anchored serine protease also implicated in epithelial homeostasis. These observations suggest that the unusually high selectivity afforded by MCoTI-II and its biological effectiveness might represent a useful starting point for the development of therapeutic inhibitors, and further highlight the role of matriptase in epithelial maintenance.

Key words: Serine protease, protease inhibitor, hepatocyte growth factor, epithelial cell, tight junctions, matriptase, cyclotide 


\section{Introduction}

Proteolytic enzymes play key regulatory roles in a wide variety of physiological and pathological process, ranging from fertility and development to cancer invasion and metastasis. The majority of these enzymes are soluble, extracellular proteins. However, a limited number are associated with the cell surface, restricting their activity to the pericellular environment and enabling them to affect cell function. This association can occur either through binding to membrane receptors or their expression as integral membrane proteins (1, 2). The latter includes matriptase, which is a member of the type-II transmembrane serine protease (TTSP) family $(2,3)$.

Matriptase is overexpressed in a wide range of human epithelial tumours, and often correlated with clinical outcome $(4,5)$. Experimental evidence suggests that the proteolytic activity of matriptase may be causally associated with tumour development, as a low level of orthotopic expression of matriptase in mice leads to spontaneous tumours and increased carcinogen susceptibility $(6,7)$. Matriptase also has essential physiological functions in regulating the integrity of epithelial tissues. Mice with targeted deletion of matriptase have a severe epidermal barrier defect leading to neonatal mortality (8), and a mutation in matriptase that leads to reduced protease activity is associated with the human syndrome autosomal recessive ichthyosis with hypotrichosis (9). Conditional deletion of matriptase in mice demonstrates that it has a more wide-ranging postnatal effect on epithelial tissues leading to severe organ dysfunction (10), and intestinal barrier competence is lost in matriptase hypomorphic mice (11).

Matriptase, in common with the other TTSPs, has trypsin-like substrate specificity, hydrolysing the peptide bond C-terminal of the Lys or Arg side-chains that occupy the S1 primary substrate specificity pocket. The extended peptide substrate specificity of matriptase has been determined $(12,13)$ and several protein substrates have been indentified in vitro. These include three proteins that can be considered to be serine protease zymogens, suggesting that matriptase is involved in zymogen activation cascades. These are the soluble serine protease uPA $(12,14,15)$, the GPI-anchored serine protease prostasin (16) and hepatocyte growth factor (HGF) $(13,14)$, a plasminogen-related growth factor also known as scatter factor. In addition to activating these substrates by limited proteolysis in purified systems, matriptase has also been shown to catalyse these reactions with high efficiency on the cell-surface. Endogenous matriptase on the surface of leukocytes has been demonstrated to proteolytically activate pro-uPA bound to its GPI-anchored cellular receptor uPAR and 
thereby facilitate pericellular plasmin generation (15), and endogenous matriptase mediates pro-HGF-dependent epithelial cell scattering (13). The proteolytic activation of each of these zymogens may potentially be involved in the pro-carcinogenic and other biological activities of matriptase $(2,7,17)$. Interestingly, another TTSP, hepsin, appears to have protein substrate specificity that overlaps to a large extent with that of matriptase,. Hepsin has been shown to activate pro-uPA, pro-HGF and pro-prostasin $(13,18-20)$, despite having a dissimilar peptide substrate specificity to that of matriptase (13).

Proteolytic enzymes as a class are considered to be a major part of the druggable genome $(21,22)$, and inhibition of matriptase activity may therefore be an attractive target for therapeutic intervention in cancer. Although effective inhibition of protease activity is easily accomplished using synthetic small molecule inhibitors, selectivity of inhibition is much more difficult to achieve, particularly between closely related proteases. The well-publicised failure of clinical trials of matrix metalloprotease inhibitors in cancer is believed to be largely a consequence of such a lack of selectivity, i.e. inhibition of metalloproteases in addition to the target, with potentially differing biological activities $(22,23)$. Therefore, the ability to discriminate between matriptase and hepsin, with their overlapping substrate specificities, must be considered to be an important goal in the development of an effective inhibitory strategy targeted at matriptase activity.

To achieve this, and to overcome the possible limitations of small molecule inhibitors, we have investigated the unique class of macrocyclic cystine-knot microproteins known as cyclotides. These plant-derived cyclic proteins include Momordica cochinchinensis trypsin inhibitor-II (MCoTI-II), a 34-residue cyclotide originally isolated from the Vietnamese squash. These cyclotides have an exceptionally rigid structure, are highly resistant to thermal and enzymatic degradation, and have a high stability in vivo (24). We have developed an efficient strategy for the total chemical synthesis of MCoTI-II, which can be used as a scaffold for the introduction of sequence variations aimed at modulating the affinity and specificity of inhibition (25-27). In the present study we have found that it is a highly specific and selective inhibitor of the biochemical and biological activities of matriptase, and that it has no detectable effect on the activity of hepsin. MCoTI-II effectively inhibits the activity of matriptase against both peptide and protein substrates, and potently inhibits the activity of matriptase in several complex cellular systems that reflect its in vivo functions. The inhibitory characteristics of MCoTI-II, and its wide-ranging biological effects, suggest that it may be a potential candidate for the development of matriptase-targeted therapeutic strategies. 


\section{Materials and methods}

\section{Proteins and reagents}

MCoTI-II, MCoTI-II[K10R], MCoTI, MCoEeT-I and MCoEeT-I[K10R] were produced by total chemical synthesis as previously described $(25,27)$. Soluble matriptase, soluble hepsin and pro-HGF (with a C-terminal V5-His tag) were all expressed and purified as previously described (13). Recombinant human kallikrein-2 (KLK2) and kallikrein-3 (KLK3) were purchased from R\&D Systems (Abingdon, UK). The fluorogenic peptide substrates H-D-ValLeu-Lys-7-amino-4-methylcoumarin and H-Glu-Gly-Arg-7-amino-4-methylcoumarin were purchased from MP Biomedicals (Cambridge, UK). Mouse anti-V5 antibody was from Invitrogen (Paisley, UK), mouse anti-prostasin from BD Biosciences (Oxford, UK), rabbit anti-claudin-1 and mouse anti-ZO-1 from Sigma-Aldrich (Poole, UK) and Alexa 488-labelled goat anti-mouse and Alexa 647-labelled goat anti-rabbit IgG from Abcam (Cambridge, UK).

\section{Cell culture}

Madine-Darby canine kidney cells (MDCK-I, MDCK-II) and HEK293 cells were routinely maintained in DMEM supplemented with 10\% FCS and 2 mM L-glutamine. PC-3 cells were maintained in RPMI medium containing 10\% FCS and $2 \mathrm{mM}$ L-glutamine. All cell culture reagents were from Invitrogen.

\section{Determination of $\mathrm{Ki}$ values for protease inhibition}

Purified soluble matriptase $(5 \mathrm{nM})$ or hepsin $(2 \mathrm{nM})$ was incubated with varying concentrations of H-D-Val-Leu-Lys-7-amino-4-methylcoumarin $(0-0.5 \mathrm{mM})$ in $50 \mathrm{mM}$ Tris$\mathrm{HCl} \mathrm{pH} 7.6,100 \mathrm{mM} \mathrm{NaCl}, 0.01 \%$ Tween 80. Varying concentrations of MCoTI-II or its derivatives were included in these incubations and substrate hydrolysis monitored continuously using a Spectramax Gemini fluorescence microplate reader (Molecular Devices, Berkshire, UK) using excitation and emission wavelengths of $360 \mathrm{~nm}$ and $440 \mathrm{~nm}$, respectively. $\mathrm{V}_{\max }$ and $\mathrm{K}_{\mathrm{m}}$ values were determined from initial reaction rates at each substrate and inhibitor concentration and $K_{i}$ values subsequently calculated from plots of $K_{m} / V_{\max }$ vs. [inhibitor], as previously described (13). For each $\mathrm{K}_{\mathrm{i}}$ determination, at least four substrate and four inhibitor concentrations were used, with each analysis performed in triplicate. $\mathrm{K}_{\mathrm{i}}$ values for other proteases were determined as previously described (27). The $\mathrm{K}_{\mathrm{i}}$ was also determined for the inhibition of pro-uPA activation using a range of pro-uPA concentrations $(0.05-1$ $\mu \mathrm{M}) . \mathrm{K}_{\mathrm{i}}$ was calculated from plots of $\mathrm{K}_{\mathrm{m}} / \mathrm{V}_{\max }$ vs. [inhibitor], as previously described (13). 


\section{Inhibition of pro-HGF and pro-uPA activation}

Purified pro-HGF or pro-uPA (both expressed in Drosophila S2 cells with a C-terminal V5epitope tag) was incubated with either soluble matriptase or soluble hepsin in $50 \mathrm{mM}$ Tris$\mathrm{HCl} \mathrm{pH} 7.6,100 \mathrm{mM} \mathrm{NaCl}, 0.01 \%$ Tween 80 , in the presence of varying concentrations of MCoTI-II. Aliquots of equal volume were taken from each reaction at timed intervals and the reaction terminated by addition of SDS-PAGE sample buffer containing dithiothreitol. Samples were analysed by SDS-PAGE and western blotting using anti-V5 primary antibody, as previously described (13).

\section{Inhibition of cell-mediated pro-HGF activation}

MDCK-II or PC-3 cells were seeded at a density of $1 \times 10^{4}$ cells per well in 96 well plates and allowed to adhere overnight. The cells were washed in serum-free medium prior to incubation with purified V5-tagged pro-HGF in the presence of MCoTI-II (100 nM or $500 \mathrm{nM}$ ). Medium was collected at timed intervals, the reaction terminated by addition of SDS-PAGE sample buffer containing dithiothreitol, and the samples analysed for pro-HGF activation by SDSPAGE and western blotting for the V5 epitope.

\section{Cell scatter assay}

The biological activity of HGF was determined by its effect on the scattering of MDCK-II cells as previously described (13). Cells were seeded at a density of $1 \times 10^{3}$ cells per well and left to adhere overnight. Pro- or active HGF $(10 \mathrm{ng} / \mathrm{ml})$ was added in the presence of varying concentrations of MCoTI-II (0 - $500 \mathrm{nM})$ in serum-free medium. After 30 hours the cells were washed twice with PBS and fixed with ice-cold methanol for 5 minutes, followed by a further PBS wash. Images were taken using a Zeiss CCD inverted microscope using x10 magnification. Treatments were performed in duplicate in three independent experiments.

\section{Matrigel invasion assay}

Precoated matrigel invasion chambers (BD Biosciences) were seeded with PC-3 cells at a density of $1 \times 10^{5}$ per in well in $200 \mu \mathrm{l}$ serum-free medium. The lower chamber contained $2 \%$ FCS as a chemoattractant and the cells were allowed to invade the matrigel for 24 hours in the presence of varying concentrations of MCoTI-II $(0-500 \mathrm{nM})$. Non-invading cells and matrigel were removed and the cells on the underside of the membrane fixed with methanol, stained with haematoxylin-eosin and mounted in hydromount (National Diagnostics, Hull, UK). Invaded cells were counted using an inverted microscope, using three randomly chosen fields for each membrane. Each experimental condition was performed in duplicate and the experiment carried out on three separate occasions. Data were analysed using Student's t-test. 


\section{Transepithelial electrical resistance (TEER) measurements}

MDCK-I cells (25,000/well) were seeded in triplicate into $6.5 \mathrm{~mm}$ Transwell chambers with $0.4 \mu \mathrm{m}$ pores (Costar, Corning Life Sciences, MA, USA). The transepithelial ion permeability of was determined every 24 hours by measuring electric resistance across the monolayer using the EVOM Epithelial Voltohmmeter (World Precision Instruments, Saratosa, FL, USA). The medium in both internal and external compartments of each Transwell was changed every 2 days, and contained varying concentrations of MCoTI-II. In $\mathrm{Ca}^{2+}$-switch experiments, cell monolayers with a stable level of TEER were incubated with Spinner's $\mathrm{Ca}^{++}$-free medium for 16 hours, followed by restoration of normal culture conditions.

\section{Immunofluorescence microscopy}

MDCK-I cells were grown on $6.5 \mathrm{~mm}$ polyester Transwell inserts with $0.4 \mu \mathrm{m}$ pores (Costar) for 5 days. Cells were fixed in methanol at $-20^{\circ} \mathrm{C}$, washed 3 times in PBS, 3 times with $1 \%$ goat serum/PBS and incubated with $10 \%$ goat serum/PBS at room temperature. Cells were incubated with primary antibodies against claudin-1 (1:100) and ZO-1 (1:50), washed and incubated with Alexa-labelled secondary antibodies (1:1000). Cells were mounted in ProLong Gold antifade reagent (Invitrogen) and images obtained using x63 magnification on a Zeiss Axiovert 200M equipped with a Zeiss AxioCam and Axiovision software.

\section{qRT-PCR}

Matriptase expression in MDCK-I and MDCK-II cells was determined by qRT-PCR using SYBR-Green chemistry (Life Technologies, Warrington, UK). First-strand cDNA was synthesised from total RNA using random hexamer priming. qRT-PCR was performed on an ABI 7700 (Life Technologies) using primers for canine matriptase; forward 5'ACAGAACCAGCAGTGTGACG-3', reverse 5'-ACTCTTCCTAACGCTGACAC-3'. Data are shown relative to the expression of $18 \mathrm{~S}$ rRNA, which was used as an endogenous control.

\section{Prostasin activation}

HEK293 cells were transfected with full-length human prostasin cDNA in pIRES2-EGFP (16) and full-length matriptase cDNA in pcDNA3.1 (13) either alone or in combination using Fugene transfection reagent under serum free conditions according to manufacturer's guidelines (Promega, Southampton, UK). Cells were incubated for 24 hours, washed and placed in serum-containing medium for a further 24 hours. Cells were lysed, samples run on SDS-PAGE under reducing conditions and western blot performed with an anti-prostasin antibody. To determine the effect of matriptase inhibition, MCoTI-II was added at 6 hours post-transfection, and added again at 24 hours when the medium was changed. 


\section{Results}

\section{Selective inhibition of matriptase by MCoTI-II}

The ability of the squash trypsin inhibitor MCoTI-II and various derivatives, with sequence variations around the reactive centre residue, to inhibit matriptase and hepsin was initially tested in solution using soluble forms of these proteases and a tripeptide fluorogenic peptide substrate. Analysis of $\mathrm{K}_{\mathrm{i}}$ values revealed that MCoTI-II was the most effective inhibitor of matriptase activity, with a $\mathrm{K}_{\mathrm{i}}$ value of $9 \mathrm{nM}$ (Table 1). Replacement of the P1 residue (Lys10) of MCoTI-II with Arg resulted in an 18-fold increase in $K_{i}$ value, consistent with the slight preference for Lys over Arg at P1 displayed by matriptase against peptide substrates (13). MCoEeTI, a hybrid with the related cystine-knot trypsin inhibitor from Ecballium elaterium (EETI-II), displayed a 60-fold increased $\mathrm{K}_{\mathrm{i}}$ value for matriptase, which in this case was slightly improved by Lys to Arg substitution at P1. The natural variant MCoTI-I, differing from MCoTI-II by two residues in a loop distal to the reactive centre loop, was also a less effective inhibitor of matriptase.

In sharp contrast, none of the inhibitors had detectable activity against the closely related type-II transmembrane serine protease, hepsin, with at least a 1000-fold difference in $\mathrm{K}_{\mathrm{i}}$ value in the case of MCoTI-II. Notably, the two variants with Arg at P1, matching the very strong P1 preference of hepsin (13), also had no detectable inhibitory activity against hepsin.

A range of other serine proteases, mainly with trypsin-like activities, were also tested. Of these, only trypsin itself and $\beta$-tryptase were inhibited to any quantifiable extent.

\section{Specific inhibition of matriptase-catalysed activation of pro-HGF by MCoTI-II}

Having established that MCoTI-II is an effective and selective inhibitor of the activity of matriptase against a small peptide substrate, we aimed to determine whether MCoTI-II was also effective in inhibiting macromolecular substrate hydrolysis. Pro-HGF has been established as a key substrate for matriptase in solution, at the cell-surface and in vivo $(7,13)$. Therefore, the effect of MCoTI-II on the activation of purified pro-HGF by soluble matriptase was investigated, using western blotting for detection. MCoTI-II was observed to completely inhibit the activation of pro-HGF at increasing concentrations (Fig. 1A, left panel). Inhibition was detectable at concentrations above $10 \mathrm{nM}$, and was essentially complete at concentrations above $100 \mathrm{nM}$ consistent with the determined $\mathrm{K}_{\mathrm{i}}$ value of $9 \mathrm{nM}$. Also consistent with our initial observations, activation of pro-HGF by soluble hepsin was not inhibited by MCoTI-II at concentrations up to $500 \mathrm{nM}$ (Fig. 1A, right panel). 
The proteolytic activation of pro-uPA by matriptase and hepsin was also affected by MCoTI-II in a manner consistent with these observations (Fig. 1B). The inhibition of matriptase-catalysed pro-uPA activation by MCoTI-II was also analysed by enzyme kinetics (Fig. 1C, left panel). From these, and similar data at other concentrations of pro-uPA, a $\mathrm{K}_{\mathrm{i}}$ value of $15 \mathrm{nM}$ was determined, in close agreement with the $\mathrm{K}_{\mathrm{i}}$ value determined directly by peptide substrate hydrolysis (Table 1). No inhibition of hepsin-catalysed pro-uPA activation was observed (Fig. 1C, right panel), consisitent with the high selectivity of MCoTI-II.

\section{Inhibition of the cellular activation of pro-HGF by MCoTI-II}

Having demonstrated the efficacy of MCoTII-II at inhibiting the proteolytic activity of matriptase in solution, its activity against endogenous, membrane-associated matriptase was investigated. We have previously demonstrated that pro-HGF is efficiently activated by the prostate cancer cell line $\mathrm{PC}-3$, and that this activation can be abolished by matriptasetargeting siRNA (13). Therefore, the ability of MCoTI-II to inhibit the cellular activation of pro-HGF was determined using this system. The data in Fig. 2 show that using $100 \mathrm{nM}$ MCoTI-II, partial and variable inhibition of pro-HGF activation was observed at two different time points, and that inhibition was essentially complete at $500 \mathrm{nM}$ of the cyclotide inhibitor. These concentrations are less than 5-fold higher than those giving comparable inhibition in the purified system, and therefore it appears that endogenous, transmembrane matriptase is completely accessible to the macromolecular inhibitor MCoTI-II.

The dog cell-line MDCK is a well-established model system used to study many aspects of epithelial biology, and may represent a useful model for the study of matriptase function. Therefore the ability of MCoTI-II to inhibit matriptase-dependent pro-HGF activation on these cells was also determined, employing the widely-used MDCK-II strain (28). The results were similar to those observed with PC-3 cells, with complete inhibition of pro-HGF activation between 100-500 nM MCoTI-II (Fig. 2). Therefore the potency of MCoTI-II is retained for the inhibition of dog matriptase, and MDCK cells can be used to further study the role of matriptase in epithelial cell function.

\section{Effect of inhibition of matriptase activity on HGF-induced cell scatter}

Binding of activated HGF to its singular cell-surface receptor c-Met causes a well-described dissolution of cell-cell junctions and scattering of MDCK-II cells, the initial stages of epithelial-mesenchymal transition. Pro-HGF cannot signal through c-Met, but cell scattering can be promoted by the pericellular proteolytic activation of pro-HGF (13). Therefore, the 
ability of MCoTI-II to inhibit cell scattering in the presence of pro-HGF was determined. MDCK-II cells at low density grow as tightly packed colonies (Fig. 3A), which disperse upon treatment with either active HGF (Fig. 3B) or pro-HGF (Fig. 3D) over a 24 hour period. Cells treated with pro-HGF and $100 \mathrm{nM}$ MCoTI-II displayed markedly less scattering (Fig. 3E), and scattering was completely abolished at $500 \mathrm{nM}$ MCoTI-II (Fig. 3F). By contrast, MCoTIII had no effect on cell scattering induced by active HGF (Fig. 3C). Therefore, inhibition of matriptase by MCoTI-II on the surface of these cells restricts the bioavailability of active HGF and its downstream effects on cell scattering.

\section{MCoTI-II can inhibit matriptase activity in complex cellular processes: invasive cell migration}

In common with a variety of other proteolytic enzymes, matriptase is implicated in invasive cell migration (29), a process occurring subsequent to EMT in epithelial carcinogenesis. To determine whether MCoTI-II could inhibit this activity, we made use of two invasive prostate cancer cell lines that differ in their levels of matriptase expression. PC-3 cells display robust expression of matriptase, but it is essentially undetectable in DU-145 cells, as determined by qRT-PCR (13). Both cell lines were found to have similar rates of invasion through the basement membrane preparation, matrigel (Fig. 4). MCoTI-II inhibited the invasion of matriptase-expressing PC-3 cells by greater than 40\%. However, MCoTI-II had no effect on the invasion of DU-145 cells, consistent with the lack of matriptase expression in these cells.

\section{MCoTI-II can inhibit matriptase activity in complex cellular processes: epithelial barrier formation}

Matriptase is known to play a role in epithelial barrier integrity in various tissues, and this can be recapitulated in cell culture (11). As we showed that MCoTI-II could inhibit matriptase activity in MDCK cells, we used these cells to study the role of matriptase in epithelial barrier formation and stability.

MDCK cells grown on semi-permeable membranes develop functional tight junctions, which display trans-epithelial electrical resistance (TEER), a functional measure of tight junction integrity. MDCK-I cells develop high TEER over time (Fig. 5A), and this is reflected by the distribution of the canonical tight junctions proteins ZO-1 and claudin-1 (Fig. 5C). MCoTI-II was found to have only a minor effect on the acquisition of TEER in these cells. Concentrations up to $1 \mu \mathrm{M}$ had no dose-dependent effect on the development of TEER up to a level of approximately $4000 \Omega . \mathrm{cm}^{2}$. Above this level, the TEER became slightly unstable and 
the presence of MCoTI-II had a minor effect on its further development. Therefore, these observations suggest that in MDCK-I cells matriptase has only a minor role in the development of a functional epithelial barrier, or is poorly inhibited by MCoTI-II.

Tight junctions are dynamic structures and can be readily disrupted by alteration of $\left[\mathrm{Ca}^{2+}\right]$ in the medium, the so-called "calcium-switch" model (30). Removal of $\mathrm{Ca}^{2+}$ from the medium rapidly disrupts tight junction structure and function, assessed by loss of membrane localisation of ZO-1 and claudin-1 (Fig. 5D) and abolition of TEER (Fig. 5B), respectively. Repletion with $\mathrm{Ca}^{2+}$ leads to a slow reestablishment of TEER (Fig. 5B) and ZO-1 and claudin1 localisation (Fig. 5E). In contrast to the lack of effect of MCoTI-II on the initial establishment of functional tight junctions, the data in Fig. 5B show that MCoTI-II had a dramatic effect on the reestablishment of TEER. At a concentration of $250 \mathrm{nM}$, MCoTI-II caused at least a 5-fold prolongation of the rate of TEER development (determined as the time taken to reach the same level of TEER), rising to 10-fold at the highest concentration used. Therefore, in MDCK-I cells, matriptase activity is involved in the dynamic behaviour of tight junction and can be effectively inhibited by MCoTI-II.

\section{MCoTI-II does not inhibit matriptase-catalysed prostasin activation}

In addition to pro-HGF, the only other substrate for matriptase that has been demonstrated in vivo is the zymogen of the GPI-anchored serine protease prostasin (16). To determine whether MCoTI-II could inhibit this process, HEK293 cells which express neither of these proteases endogenously were transfected with both matriptase and prostasin. Cells transfected with prostasin alone displayed a single band of approximately $41 \mathrm{kDa}$ on western blot corresponding to the inactive zymogen form of prostasin (Fig. 6). Co-transfection with matriptase led to complete activation of prostasin, with a single band observed at $38 \mathrm{kDa}$ representing the $\mathrm{C}$-terminal part of the protein after proteolytic activation at Arg-18. In contrast to the activation of pro-HGF, inclusion of MCoTI-II was unable to inhibit the matriptase-catalysed activation of pro-prostasin. In these experiments MCoTI-II was initially added 24 hours after transfection and incubated for a further 24 hours, without effect. Subsequently MCoTI-II was included directly after transfection of the cells, but inhibition of prostasin activation was still not observed (Fig. 6). 


\section{Discussion}

In the present study we have found that the cyclic cystine-knot microprotein MCoTI-II is an effective and specific inhibitor of the catalytic activity of the type-II transmembrane serine protease matriptase, influencing several biological functions that mirror the role of matriptase in vivo. Using a combination of biochemical and cell biological approaches we show that MCoTI-II efficiently inhibits the proteolytic activation of pro-HGF at the surface of matriptase-expressing cells, reducing the bioavailability of HGF and the induction of c-Metdependent cell-scattering. MCoTI-II was also found to inhibit the invasive migration of PC-3 prostate carcinoma cells. In addition to these activities of matriptase that may underpin its involvement in cancer, MCoTI-II was also found to affect epithelial tight junction dynamics, potentially giving insights into the poorly understood role of matriptase in this process. Despite its efficacy, MCoTI-II was unable to inhibit the cellular activation of prostasin, a serine protease regarded as another major substrate for matriptase in vivo.

Achieving specificity of inhibition and selectivity between enzymes with similar activities is one of the main challenges in the therapeutic use of inhibitors, and this is particularly true for proteolytic enzymes (31). In the case of matriptase, hepsin is a closely related protease that shares overlapping protein substrate specificity:.it can activate pro-HGF at the cell surface (13), and also activate both pro-uPA and pro-prostasin $(19,20)$. Therefore, the ability of MCoTI-II to discriminate between matriptase and hepsin, with a greater than 1000-fold differential in $\mathrm{K}_{\mathrm{i}}$ values is an important feature of its inhibitory activity. The reason for this exceptional level of discrimination is not immediately clear, but matriptase and hepsin have significant differences in the loop regions surrounding the active site that are often responsible for modulating substrate accessibility (32). Matriptase has a large 60s insertion loop, which has been shown to engage in favourable electrostatic interactions with the Kunitz-type inhibitor BPTI, (33), and is modelled in proximity to Arg16-Arg17 of MCoTI-II (34). The equivalent loop in hepsin is 4-residues shorter and has a higher net positive charge, possibly disfavouring such interactions with MCoTI-II. The 90s-loop is also unusually large in hepsin which, based on the previous modelling with matriptase, may restrict access of MCoTI-II by sterically hindering the loop delimited by Cys 21 and Cys 25 of the inhibitor. Interestingly, although the inhibitory characteristics of MCoTI-II were determined using human matriptase, the experiments with MDCK cells demonstrate that it has a similar inhibitory potency against canine matriptase. This apparent lack of species specificity may prove to be useful, for example, in inhibiting matriptase activity in various animal models. 
Our study confirms and extends the findings of a recent report demonstrating that MCoTIII is more potent than sunflower trypsin inhibitor (SFTI) as an inhibitor of matriptase in purified systems (34). This study also identified the variant MCoTI-II [V3R] (V7R in the numbering system used here) as having a 10-fold lower $\mathrm{K}_{\mathrm{i}}$ value than the wild-type sequence. Several other macromolecular inhibitors have been shown to inhibit matriptase activity in purified systems, including variants of the natural protease inhibitors ecotin, eglin C and SFTI (35-38), although neither their efficacy in cellular systems nor their inhibitory activity towards hepsin have been reported. Irrespective of their affinity for matriptase, all of these inhibitors retain substantial inhibitory activity towards pancreatic trypsin, as also observed here for MCoTI-II. Whether this might contribute to potential biological effects of MCoTI-II (or other inhibitors of matriptase) via inhibition of non-pancreatic trypsin (mesotrypsin, PRSS3), which plays a role in several malignancies including prostate cancer, is not known, although this form of trypsin has been shown to be poorly inhibited by canonical trypsin inhibitors (39).

Several small molecule inhibitors of matriptase have been developed, and some shown to be effective in vivo using xenograft models of tumour growth, albeit at high concentrations $(40,41)$. However, the inhibitory activity of these compounds against hepsin has not been reported, and our own data with the 3-amidinophenylalanine-based inhibitor CJ-730 (41) demonstrated a less than 5-fold selectivity between matriptase and hepsin,(13). Another disadvantage apparent with small molecule inhibitors is their efficacy in complex cellular systems is far lower than suggested by $\mathrm{K}_{\mathrm{i}}$ values determined in solution. For example, an approximately 100-fold differential has been observed between the $\mathrm{K}_{\mathrm{i}}$ values and the estimated $\operatorname{IC}_{50}$ values for the cellular activation of pro-HGF $(13,29)$, and 300 -fold for the autoactivation of matriptase (42). This is in marked contrast to the efficacy of MCoTI-II in cellular systems, which demonstrates essentially complete inhibition of the cellular activities of matriptase at concentrations 10-20-fold above the $\mathrm{K}_{\mathrm{i}}$ value; entirely consistent with full bioavailability of the inhibitor in these complex systems.

Matriptase inhibition by MCoTI-II was found to inhibit the formaton of functional tight

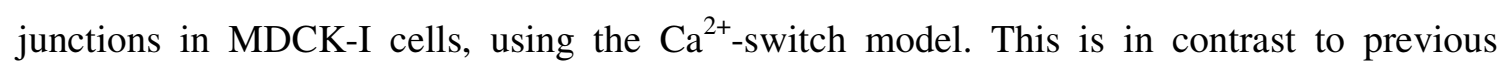
observations with overexpression of HAI-2, which was observed to increase the rate of acquisition of TEER in these cells (43). Although HAI-2 is clearly a major inhibitor of matriptase in vivo (43), it lacks selectivity, inhibiting a wide range of serine proteases in vitro (44), and, unlike MCoTI-II, inhibiting matriptase and hepsin equally well (18). Therefore, HAI-2 potentially inhibits a trypsin-like protease that acts to increase epithelial permeability, for example, by the degradation of junctional proteins $(45,46)$. Consistent with our 
observations, siRNA silencing of matriptase in human Caco-2 epithelial cells has been shown to delay the reestablishment of TEER, as well as its initial acquisition $(11,47)$. The mechanism by which matriptase influences the behaviour of epithelial tight junctions is poorly understood, but appears to be independent of its established protein substrates (11).

Despite the poor understanding of the role of matriptase in regulating epithelial barrier function, there is compelling evidencefor two authentic substrates in vivo, both of which have important roles in epithelial cell function. A mouse model of matriptase-initiated squamous cell carcinoma has been shown to be absolutely dependent on the presence of c-Met, directly implicating pro-HGF as a key substrate for matriptase (7). We demonstrate here that MCoTIII can effectively inhibit the activation of pro-HGF, both in MDCK and PC-3 cells, and that it was also able to inhibit the cell-scattering that is a central to the biological activity of HGF. The observation that MCoTI-II was able to inhibit the invasion of PC-3 cells suggests that matriptase can also promote carcinogenesis in an HGF-independent manner, possibly by direct effect on extracellular matrix proteins or by activation of the plasminogen activation system $(15,48)$. Members of the kallikrein-related family of serine proteases are thought to play significant roles in several of these process, but MCoTI-II was found to have no inhibitory activity towards either KLK2 (glandular kallikrein) or KLK3 (prostate-specific antigen), although neither of these proteases is highly expressed in PC-3 cells.

The second substrate for matriptase demonstrated in vivo is the zymogen of the GPIanchored serine protease, prostasin (16). However, despite the efficacy of MCoTI-II, the activation of prostasin by matriptase was unaffected by MCoTI-II. This is potentially related to several unusual characteristics reported for this reaction. It has been suggested that prostasin activation is temporally coupled to matriptase activation (49) and that the latter can occur intracellularly (50) and, intriguingly, that prostasin can be activated by the zymogen form of matriptase (51). In either of these situations, the activation of prostasin might be expected to be refractory to inhibition by MCoTI-II. However, it cannot be completely excluded that our observation is related to limitations imposed by the extraordinary efficiency of prostasin activation, as we observe its complete activation when coexpressed with matriptase. However, inclusion of MCoTI-II for the duration of the experiment failed to affect prostasin activation; conditions where a steady-state level of the zymogen might be expected to accumulate.

The specific and selective inhibition of matriptase activity by the macrocyclic cystine-knot microprotein MCoTI-II observed here in complex cellular systems demonstrates the potential usefulness of this type of inhibitor in the development of protease-targeted therapies. MCoTI- 
II has the ability to efficiently inhibit the activation of pro-HGF and HGF-dependent cell scattering, and invasive cell migration; processes closely linked to pathological events, particularly in cancer. Intriguingly, the lack of effect of MCoTI-II on prostasin activation may also be therapeutically beneficial, as the roles of matriptase in normal physiology are largely prostasin-dependent; highlighted be the similarity in the phenotypes of the respective null mice (16). In addition to its pro-carcinogenic roles, matriptase has been shown to have tumour-suppressive effects in colon carcinogenesis (52), consistent with its role in the maintenance of the epithelial barrier, as recapitulated here in MDCK-I cells. These opposing roles of matriptase in the initiation and progression of cancer highlight the importance of gaining a deeper understanding of the functions of matriptase in regulating epithelial cell behaviour for the development of potential therapeutic strategies. Highly specific matriptase inhibitors such as MCoTI-II and the MDCK cell model system described here may help contribute to this understanding.

\section{Conflicts of interest}

None of the authors declare any conflicts of interest. 


\section{References}

1. Ellis V, Murphy G. Cellular strategies for proteolytic targeting during migration and invasion. FEBS Lett 2001; 506: 1-5.

2. Qiu D, Owen K, Gray K, et al. Roles and regulation of membrane-associated serine proteases. Biochem Soc Trans 2007; 35: 583-587.

3. Szabo R, Wu Q, Dickson RB, et al. Type II transmembrane serine proteases. Thromb Haemost 2003; 90: 185-193.

4. Kang JY, Dolled-Filhart M, Ocal IT, et al. Tissue Microarray Analysis of Hepatocyte Growth Factor/Met Pathway Components Reveals a Role for Met, Matriptase, and Hepatocyte Growth Factor Activator Inhibitor 1 in the Progression of Node-negative Breast Cancer. Cancer Res 2003; 63: 1101-1105.

5. Riddick AC, Shukla CJ, Pennington CJ, et al. Identification of degradome components associated with prostate cancer progression by expression analysis of human prostatic tissues. Br J Cancer 2005; 92: 2171-2180.

6. List K, Szabo R, Molinolo A, et al. Deregulated matriptase causes ras-independent multistage carcinogenesis and promotes ras-mediated malignant transformation. Genes Dev 2005; 19: 1934-1950.

7. Szabo R, Rasmussen AL, Moyer AB, et al. c-Met-induced epithelial carcinogenesis is initiated by the serine protease matriptase. Oncogene 2011; 30: 2003-2016.

8. List K, Haudenschild CC, Szabo R, et al. Matriptase/MT-SP1 is required for postnatal survival, epidermal barrier function, hair follicle development, and thymic homeostasis. Oncogene 2002; 21: 3765-3779.

9. Basel-Vanagaite L, Attia R, Ishida-Yamamoto A, et al. Autosomal recessive ichthyosis with hypotrichosis caused by a mutation in ST14, encoding type II transmembrane serine protease matriptase. Am J Hum Genet 2007; 80: 467-477.

10. List K, Kosa P, Szabo R, et al. Epithelial integrity is maintained by a matriptasedependent proteolytic pathway. Am J Pathol 2009; 175: 1453-1463.

11. Buzza MS, Netzel-Arnett S, Shea-Donohue T, et al. Membrane-anchored serine protease matriptase regulates epithelial barrier formation and permeability in the intestine. Proc Natl Acad Sci U S A 2010; 107: 4200-4205.

12. Takeuchi T, Harris JL, Huang W, et al. Cellular localization of membrane-type serine protease 1 and identification of protease-activated receptor- 2 and single-chain urokinasetype plasminogen activator as substrates. J Biol Chem 2000; 275: 26333-26342.

13. Owen KA, Qiu D, Alves J, et al. Pericellular activation of hepatocyte growth factor by the transmembrane serine proteases matriptase and hepsin, but not by the membraneassociated protease uPA. Biochem J 2010; 426: 219-228.

14. Lee SL, Dickson RB, Lin CY. Activation of hepatocyte growth factor and Urokinase/Plasminogen activator by matriptase, an epithelial membrane serine protease. $\mathbf{J}$ Biol Chem 2000; 275: 36720-36725.

15. Kilpatrick LM, Harris RL, Owen KA, et al. Initiation of plasminogen activation on the surface of monocytes expressing the type II transmembrane serine protease matriptase. Blood 2006; 108: 2616-2623.

16. Netzel-Arnett S, Currie BM, Szabo R, et al. Evidence for a matriptase-prostasin proteolytic cascade regulating terminal epidermal differentiation. J Biol Chem 2006; 281: 32941-32945. 
17. Bugge TH, Antalis TM, Wu Q. Type II transmembrane serine proteases. J Biol Chem 2009; 284: 23177-23181.

18. Kirchhofer D, Peek M, Lipari MT, et al. Hepsin activates pro-hepatocyte growth factor and is inhibited by hepatocyte growth factor activator inhibitor-1B (HAI-1B) and HAI-2. FEBS Lett 2005; 579: 1945-1950.

19. Moran P, Li W, Fan B, et al. Pro-urokinase-type plasminogen activator is a substrate for hepsin. J Biol Chem 2006; 281: 30439-30446.

20. Chen MQ, Chen LM, Lin CY, et al. Hepsin activates prostasin and cleaves the extracellular domain of the epidermal growth factor receptor. Mol Cell Biochem 2010; 337: 259-266.

21. Hopkins AL, Groom CR. The druggable genome. Nat Rev Drug Discov 2002; 1: 727-730.

22. Overall CM, Lopez-Otin C. Strategies for MMP inhibition in cancer: innovations for the post-trial era. Nat Rev Cancer 2002; 2: 657-672.

23. Coussens LM, Fingleton B, Matrisian LM. Matrix metalloproteinase inhibitors and cancer: trials and tribulations. Science 2002; 295: 2387-2392.

24. Werle M, Kafedjiiski K, Kolmar H, et al. Evaluation and improvement of the properties of the novel cystine-knot microprotein McoEeTI for oral administration. International Journal of Pharmaceutics 2007; 332: 72-79.

25. Thongyoo P, Tate EW, Leatherbarrow RJ. Total synthesis of the macrocyclic cysteine knot microprotein MCoTI-II. Chem Commun (Camb ) 2006; 2848-2850.

26. Thongyoo P, Jaulent AM, Tate EW, et al. Immobilized protease-assisted synthesis of engineered cysteine-knot microproteins. Chembiochem 2007; 8: 1107-1109.

27. Thongyoo P, Bonomelli C, Leatherbarrow RJ, et al. Potent inhibitors of beta-tryptase and human leukocyte elastase based on the MCoTI-II scaffold. J Med Chem 2009; 52: 61976200 .

28. Dukes JD, Whitley P, Chalmers AD. The MDCK variety pack: choosing the right strain. BMC Cell Biology 2011; 12:

29. Förbs D, Thiel S, Stella MC, et al. In vitro inhibition of matriptase prevents invasive growth of cell lines of prostate and colon carcinoma. Int J Oncol 2005; 27: 1061-1070.

30. Nigam SK, Rodriguez-Boulan E, Silver RB. Changes in intracellular calcium during the development of epithelial polarity and junctions. PNAS 1992; 89: 6162-6166.

31. Deu E, Verdoes M, Bogyo M. New approaches for dissecting protease functions to improve probe development and drug discovery. Nat Struct Mol Biol 2012; 19: 9-16.

32. Bode W, Turk D, Karshikov A. The refined 1.9-Ã... X-ray crystal structure of d-Phe-ProArg chloromethylketone-inhibited human I İ-thrombin: Structure analysis, overall structure, electrostatic properties, detailed active-site geometry, and structure-function relationships. Protein Sci 1992; 1: 426-471.

33. Friedrich R, Fuentes-Prior P, Ong E, et al. Catalytic domain structures of MTSP1/matriptase, a matrix-degrading transmembrane serine proteinase. J Biol Chem 2002; 277: 2160-2168.

34. Quimbar P, Malik U, Sommerhoff CP, et al. High-affinity cyclic peptide matriptase inhibitors. J Biol Chem 2013; Papers in Press M113.460030:

35. Stoop AA, Craik CS. Engineering of a macromolecular scaffold to develop specific protease inhibitors. Nat Biotechnol 2003; 21: 1063-1068. 
36. Desilets A, Longpre JM, Beaulieu ME, et al. Inhibition of human matriptase by eglin c variants. FEBS Lett 2006; 580: 2227-2232.

37. Li P, Jiang S, Lee SL, et al. Design and synthesis of novel and potent inhibitors of the type II transmembrane serine protease, matriptase, based upon the sunflower trypsin inhibitor1. J Med Chem 2007; 50: 5976-5983.

38. Fittler H, Avrutina O, Glotzbach B, et al. Combinatorial tuning of peptidic drug candidates: high-affinity matriptase inhibitors through incremental structure-guided optimization. Organic \& Biomolecular Chemistry 2013; 11: 1848-1857.

39. Salameh MA, Soares AS, Navaneetham D, et al. Determinants of Affinity and Proteolytic Stability in Interactions of Kunitz Family Protease Inhibitors with Mesotrypsin. J Biol Chem 2010; 285: 36884-36896.

40. Galkin AV, Mullen L, Fox WD, et al. CVS-3983, a selective matriptase inhibitor, suppresses the growth of androgen independent prostate tumor xenografts. Prostate 2004; 61: 228-235.

41. Steinmetzer T, Schweinitz A, Sturzebecher A, et al. Secondary amides of sulfonylated 3amidinophenylalanine. New potent and selective inhibitors of matriptase. J Med Chem 2006; 49: 4116-4126.

42. $\mathrm{Xu} \mathrm{ZH}$, Chen $\mathrm{YW}$, Battu A, et al. Targeting zymogen activation to control the matriptaseprostasin proteolytic cascade. J Med Chem 2011; 54: 7567-7578.

43. Szabo R, Hobson JP, Christoph K, et al. Regulation of cell surface protease matriptase by HAI2 is essential for placental development, neural tube closure and embryonic survival in mice. Development 2009; 136: 2653-2663.

44. Delaria KA, Muller DK, Marlor CW, et al. Characterization of placental bikunin, a novel human serine protease inhibitor. J Biol Chem 1997; 272: 12209-12214.

45. Scudamore CL, Jepson MA, Hirst BH, et al. The rat mucosal mast cell chymase, RMCPII, alters epithelial cell monolayer permeability in association with altered distribution of the tight junction proteins ZO-1 and occludin. Eur J Cell Biol 1998; 75: 321-330.

46. Willemsen LEM, Hoetjes JP, Van Deventer SJH, et al. Abrogation of IFN-g mediated epithelial barrier disruption by serine protease inhibition. Clinical \& Experimental Immunology 2005; 142: 275-284.

47. Buzza MS, Martin EW, Driesbaugh KH, et al. Prostasin Is Required for Matriptase Activation in Intestinal Epithelial Cells to Regulate Closure of the Paracellular Pathway. J Biol Chem 2013; 288: 10328-10337.

48. Tripathi M, Potdar AA, Yamashita H, et al. Laminin-332 cleavage by matriptase alters motility parameters of prostate cancer cells. Prostate 2011; 71: 184-196.

49. Chen YW, Wang JK, Chou FP, et al. Regulation of the matriptase-prostasin cell surface proteolytic cascade by hepatocyte growth factor activator inhibitor-1 during epidermal differentiation. J Biol Chem 2010; 285: 31755-31762.

50. Tseng IC, Xu H, Chou FP, et al. Matriptase activation, an early cellular response to acidosis. J Biol Chem 2010; 285: 3261-3270.

51. Friis S, Uzzun Sales K, Godiksen S, et al. A matriptase-prostasin reciprocal zymogen activation complex with unique features: Prostasin as a non-enzymatic co-factor for matriptase activation. J Biol Chem 2013; 288: 19028-19039.

52. Kosa P, Szabo R, Molinolo AA, et al. Suppression of Tumorigenicity-14, encoding matriptase, is a critical suppressor of colitis and colitis-associated colon carcinogenesis. Oncogene 2012; 31: 3679-3695. 


\section{FIGURE LEGENDS}

\section{FIGURE 1. MCoTI-II specifically inhibits matriptase-catalysed activation of pro-HGF} and pro-uPA. (A) Varying concentrations of MCoTI-II were incubated with either soluble matriptase ( $1 \mathrm{nM}$, left panel) or soluble hepsin $(10 \mathrm{nM}$, right panel $)$ and pro-HGF for 2 hours at $37^{\circ} \mathrm{C}$. Activation of pro-HGF was determined by SDS-PAGE of reduced samples followed by western blotting for the C-terminal V5 epitope. (B) Varying concentrations of MCoTI-II were incubated with either soluble matriptase $(1 \mathrm{nM}$, left panel $)$ or soluble hepsin $(10 \mathrm{nM}$, right panel) and pro-uPA for 1 hour at $37^{\circ} \mathrm{C}$. Activation of pro-uPA was determined by SDSPAGE of reduced samples followed by western blotting for the C-terminal V5 epitope. (C) The generation of uPA activity by either soluble matriptase $(1 \mathrm{nM}$, left panel $)$ or soluble hepsin (1 nM, right panel) was determined in the presence of varying concentrations of $\operatorname{MCoTI}-\mathrm{II}(\square), \square 30, \Delta 100, \bigcirc 300, \diamond 1000 \mathrm{nM})$ and expressed as change in fluorescence/min for the hydrolysis of the uPA-specific substrate H-Glu-Gly-Arg-7-amino-4methylcoumarin.

FIGURE 2. MCoTI-II inhibits the cellular activation of pro-HGF. MDCK-II or PC-3 cells were incubated with pro-HGF in the presence and absence of MCoTI-II (100 and $500 \mathrm{nM})$. Medium was removed at timed intervals, samples resolved by SDS-PAGE under reducing conditions and activation of pro-HGF determined by western blotting for the C-terminal V5 epitope. Data shown are at 2 hours (left) and 4 hours (right) for PC-3 cells, and 4 hours incubation for MDCK-II cells. Control lanes are pro-HGF incubated in medium alone, and display a low molecular weight band due to traces of active, two-chain HGF as a minor contaminant in the purified protein preparation (13).

FIGURE 3. Effect of inhibition of matriptase activity on HGF-induced cell scattering. MDCK cells were seeded at a density of $10^{3}$ cells per well. Cells were treated with pro-HGF $(10 \mathrm{ng} / \mathrm{ml})$ in serum-free medium in the presence of $100 \mathrm{nM}$ or $500 \mathrm{nM}$ MCoTI-II for 24 hours at $37^{\circ} \mathrm{C}$. Cells treated with active HGF $(10 \mathrm{ng} / \mathrm{ml})$ and cells without HGF treatment served as positive and negative controls respectively. Cells were fixed with ice cold methanol for 5 minutes and images taken using the Zeiss CCD inverted microscope using a $\mathrm{x} 10$ magnification. Data are representative of three separate experiments performed in duplicate. 
FIGURE 4. Effect of MCoTI-II on cell invasion. Invasion of PC-3 and DU-145 cells through matrigel-coated semi-permeable membranes, in response to $2 \% \mathrm{FCS}$, was determined in the absence (solid bars) and presence of 100 and $500 \mathrm{nM}$ MCoTI-II (open bars, concentrations indicated below) over a 24 hour time period. Data are shown as cell number invaded per microscopic field (mean +/- SEM). Statistical differences between inhibitortreated and untreated cells were assessed by Student's t-test $(* \mathrm{p}<0.05)$.

FIGURE 5. MCoTI-II abolishes the reestablishment of tight junctions in MDCK-I cells.

(A) MDCK-I cells were grown on Transwell filters in the absence $(\bullet)$ or presence of varying concentrations of MCoTI-II ( $\square 250 \mathrm{nM}, \diamond 500 \mathrm{nM}, \circ 1000 \mathrm{nM})$ and transepithelial electrical resistance (TEER) measured. (B) MDCK-I cells with high TEER were disrupted by removal of $\mathrm{Ca}^{2+}$ for 16 hrs (dashed line) prior to repletion with $\mathrm{Ca}^{2+}$. MCoTI-II concentrations as in panel A. In all experiments MCoTI-II was included at each change of culture medium. All TEER data shown are means of triplicate determinations. (C-E) Indirect immunofluorescence staining for tight junction proteins in MDCK-I cells grown on Transwell filters as for the TEER experiments. (C) Prior to $\mathrm{Ca}^{2+}$-switch, (D) after $\mathrm{Ca}^{2+}$-depletion, (E) after $\mathrm{Ca}^{2+}$-repletion for 24 hrs. Each panel shows claudin-1 staining (green), ZO-1 staining (red) and colocalization (yellow). Loss of claudin-1 (green) and ZO-1 (red) localisation is apparent during the $\mathrm{Ca}^{2+}$-switch due to disruption of tight junctions, correlating with the changes in TEER shown in panel $B$.

FIGURE 6. Effect of MCoTI-II on activation of prostasin zymogen. HEK-293 cells were transfected with either prostasin alone or cotransfected with both prostasin and matriptase. MCoTI-II (500 nM) was incubated with the cells 6 hours after transfection. Cell lysates were collected at 48 hours post-transfection and subjected to SDS-PAGE and western blot for prostasin. Prostasin zymogen is detected at $41 \mathrm{kDa}$ in the cells transfected with prostasin alone, and the N-terminally truncated activated form is detected at $38 \mathrm{kDa}$ in the cells cotransfected with matriptase. 


\section{What is known about this topic?}

- Matriptase is involved in a range of biological processes and these may be mediated by a range of protein substrates for this protease.

- The closely related protease hepsin shares several different protein substrates with matriptase, yet has distinct biological functions.

- Efforts to inhibit the proteolytic activity of matriptase are hampered by lack of specificity/selectivity of small molecule inhibitors.

\section{What does this paper add?}

- The cyclic microprotein MCoTI-II is identified as a high affinity inhibitor of matriptase that is highly selective with respect to inhibition of hepsin.

- MCoTI-II efficiently inhibits the activity of matriptase against several of its known protein substrates in both purified and complex cellular systems.

- MCoTI-II also inhibits the activity of matriptase that is required to maintain epithelial barrier function via an as yet unknown substrate.

- The class of protease inhibitors exemplified by MCoTI-II have potential as highly selective inhibitors of matriptase in biological systems. 
Table 1:Equilibrium dissociation constants $\left(\mathrm{K}_{\mathrm{i}}\right)$ for MCoTI-II derivatives

\begin{tabular}{|l|c|c|c|c|c|}
\hline \multirow{2}{*}{ Protease } & \multicolumn{5}{|c|}{$\mathrm{K}_{\mathrm{i} \text { value }(\mathrm{nM})}$} \\
\cline { 2 - 6 } & MCoTI-II & $\begin{array}{c}\text { MCoTI-II } \\
\text { [K10R] }\end{array}$ & MCoTI-I & MCoEeTI & $\begin{array}{c}\text { MCoEeTI } \\
{[\text { K10R }]}\end{array}$ \\
\hline Matriptase & $9.0 \pm 1^{\mathrm{b}}$ & $158 \pm 46$ & $155 \pm 31$ & $570 \pm 85$ & $370 \pm 60$ \\
\hline Hepsin $^{\mathrm{c}}$ & $>10^{4}$ & $>10^{4}$ & $>10^{4}$ & $>10^{4}$ & $>10^{4}$ \\
\hline Trypsin & $0.075 \pm 0.005$ & $0.085 \pm 0.007$ & $0.029 \pm 0.002$ & $48 \pm 5$ & $8.8 \pm 0.3$ \\
\hline Chymotrypsin & $>10^{4}$ & $>10^{4}$ & $>10^{4}$ & ND & ND \\
\hline Thrombin & $>10^{5}$ & $>10^{5}$ & $>10^{5}$ & ND & ND \\
\hline uPA & $>10^{5}$ & $>10^{5}$ & ND & ND & ND \\
\hline KLK2 & $>10^{4}$ & $>10^{4}$ & ND & ND & ND \\
\hline KLK3 & $>10^{4}$ & $>10^{4}$ & ND & ND & ND \\
\hline HLE & $>10^{\mathrm{d}}$ & $>10^{5}$ & $>10^{5}$ & ND & ND \\
\hline$\beta$-tryptase & $600 \pm 30$ & $120 \pm 50$ & $1600 \pm 140$ & $33 \pm 7$ & $28 \pm 2$ \\
\hline Subtilisin & $>10^{5}$ & $>10^{5}$ & $>10^{5}$ & ND & ND \\
\hline
\end{tabular}

(a) The amino acid sequences of these cyclic proteins, with P1 residue on bold and variations from the native MCoTI-II sequence underlined, are:

MCoTI-II, SGSDGGVCPKILKKCRRDSDCPGACICRGNGYCG;

MCOTI-II[K10R], SGSDGGVCPRILKKCRRDSDCPGACICRGNGYCG;

MCOTI-I, SGSDGGVCPKILQRCRRDSDCPGACICRGNGYCG;

MCoEeTI, SG----VCPKILKKCRRDSDCLAGCECGPNGYCG;

MCoEeTI[K10R], SG----VCPRILKKCRRDSDCLAGCECGPNGYCG.

(b) Data are shown for soluble matriptase catalytic domain (expressed in E.coli), but $\mathrm{K}_{\mathrm{i}}$ values were essentially unchanged using full-length soluble matriptase (expressed in Drosophila S2 cells).

(c) The maximum concentration of each inhibitor used was at least $2 \mu \mathrm{M}$, giving an estimated minimum $\mathrm{K}_{\mathrm{i}}$ value of $10 \mu \mathrm{M}$ in the absence of detectable inhibition.

(d) Human leukocyte elastase

(e) Not determined 


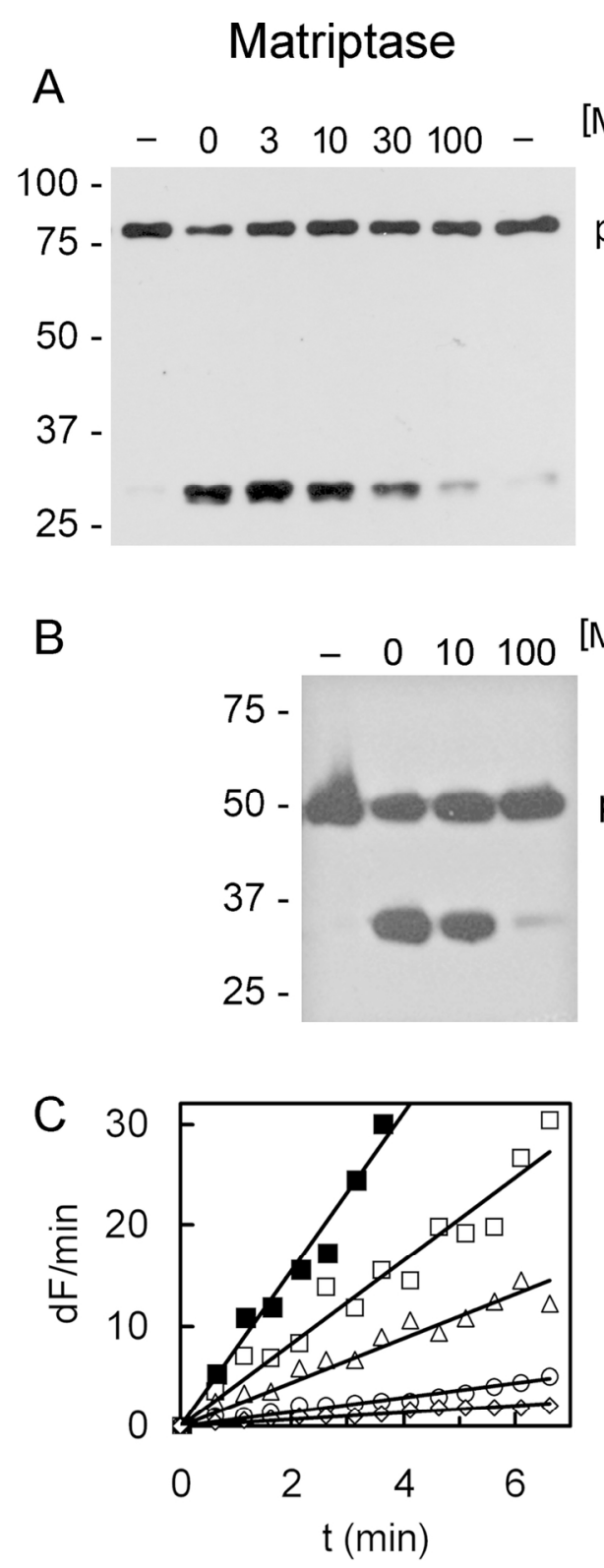

Hepsin
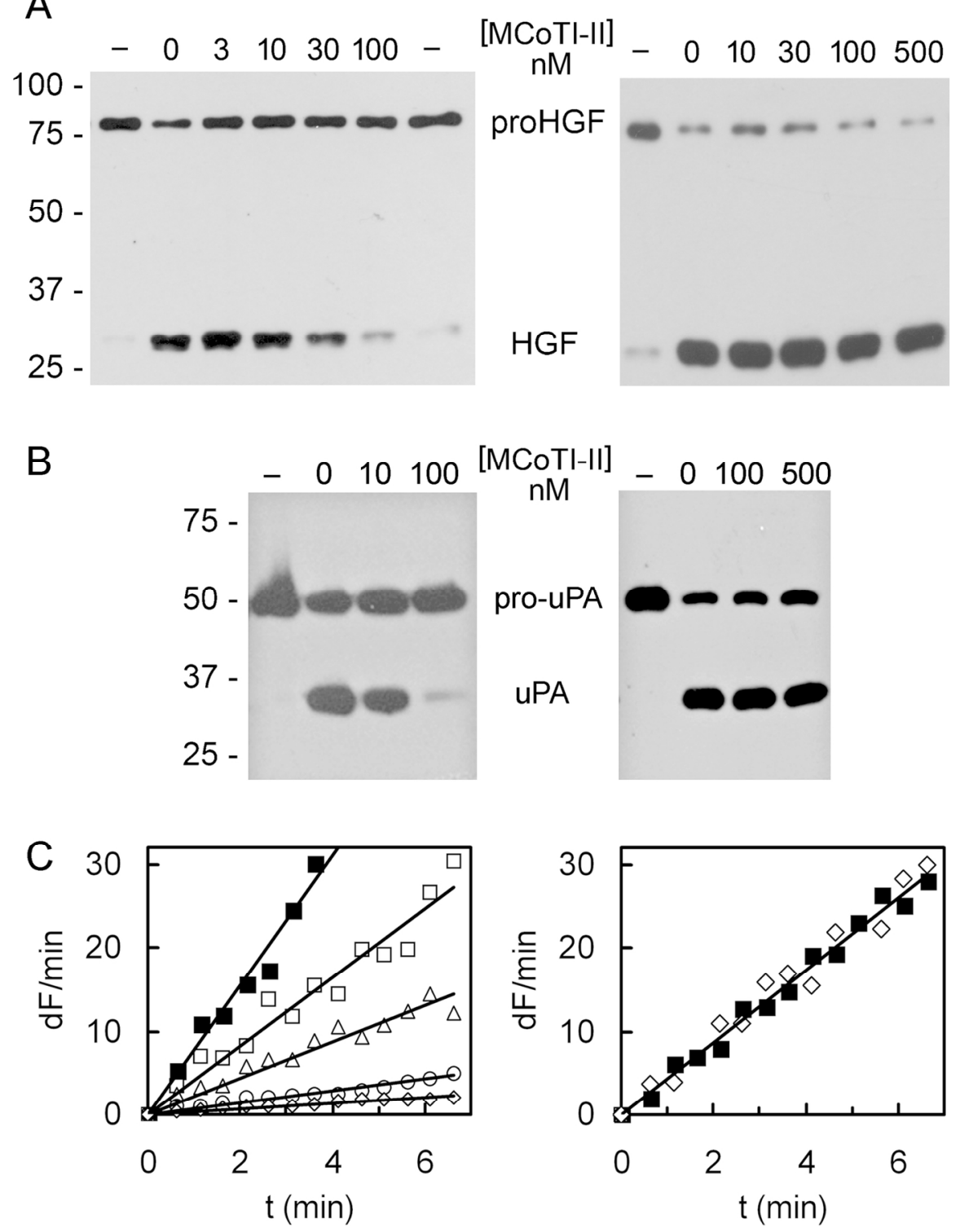

FIGURE 1. MCoTI-II specifically inhibits matriptase-catalysed activation of pro-HGF and pro-uPA

(A) Varying concentrations of MCOTI-II were incubated with either soluble matriptase (1 nM, left panel) or soluble hepsin (10 nM, right panel) and pro-HGF for 2 hours at $37^{\circ} \mathrm{C}$. Activation of pro-HGF was determined by SDS-PAGE of reduced samples followed by western blotting for the C-terminal V5 epitope. (B) Varying concentrations of MCOTI-II were incubated with either soluble matriptase (1 nM, left panel) or soluble hepsin (10 nM, right panel) and pro-uPA for 1 hour at $37^{\circ} \mathrm{C}$. Activation of pro-uPA was determined by SDS-PAGE of reduced samples followed by western blotting for the C-terminal V5 epitope. (C) The generation of uPA activity by either soluble matriptase ( $1 \mathrm{nM}$, left panel) or soluble hepsin (1 nM, right panel) was determined in the presence of varying concentrations of MCoTI-II $(\bullet 0, \bullet 30, \Delta 100, \Upsilon 300, \diamond 1000 \mathrm{nM})$ and expressed as change in fluorescence/min for the hydrolysis of the uPA-specific substrate Glu-Gly-Arg-7-AMC. $133 \times 180 \mathrm{~mm}(300 \times 300 \mathrm{DPI})$ 


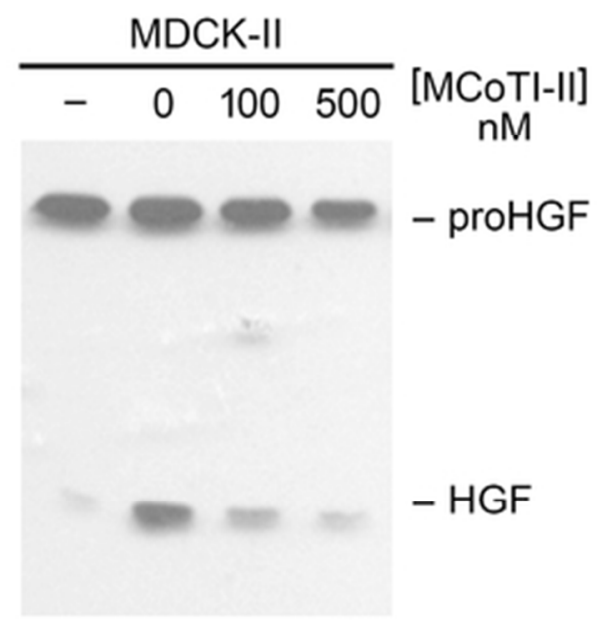

FIGURE 2. MCOTI-II inhibits the cellular activation of pro-HGF. MDCK-II or PC-3 cells were incubated with pro-HGF in the presence and absence of MCOTI-II (100 and $500 \mathrm{nM}$ ). Medium was removed at timed intervals, samples resolved by SDS-PAGE under reducing conditions and activation of pro-HGF determined by western blotting for the C-terminal V5 epitope. Data shown are at 2 hours (left) and 4 hours (right) for PC-3 cells, and 4 hours incubation for MDCK-II cells. Control lanes are pro-HGF incubated in medium alone, and display a low molecular weight band due to traces of active, two-chain HGF as a minor contaminant in the purified protein preparation. $48 \times 22 \mathrm{~mm}(300 \times 300 \mathrm{DPI})$ 


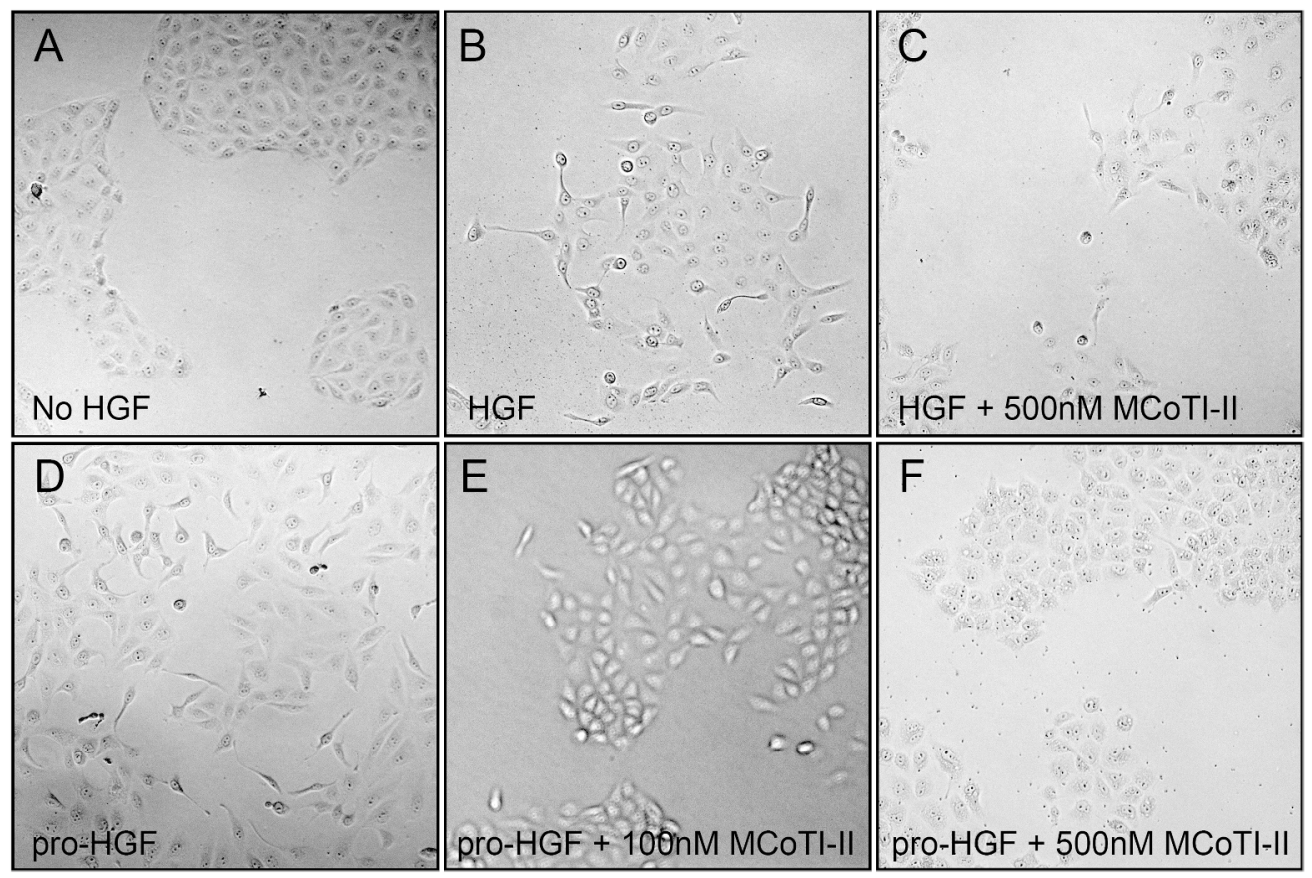

FIGURE 3. Effect of inhibition of matriptase activity on HGF-induced cell scattering. MDCK cells were seeded at a density of $10^{3}$ cells per well. Cells were treated with pro-HGF $(10 \mathrm{ng} / \mathrm{ml})$ in serum-free medium in the presence of $100 \mathrm{nM}$ or $500 \mathrm{nM}$ MCoTI-II for 24 hours at $37^{\circ} \mathrm{C}$. Cells treated with active HGF $(10 \mathrm{ng} / \mathrm{ml})$ and cells without HGF treatment served as positive and negative controls respectively. Cells were fixed with ice cold methanol for 5 minutes and images taken using the Zeiss CCD inverted microscope using a x10 magnification. Data are representative of three separate experiments performed in duplicate. $246 \times 164 \mathrm{~mm}(300 \times 300 \mathrm{DPI})$ 


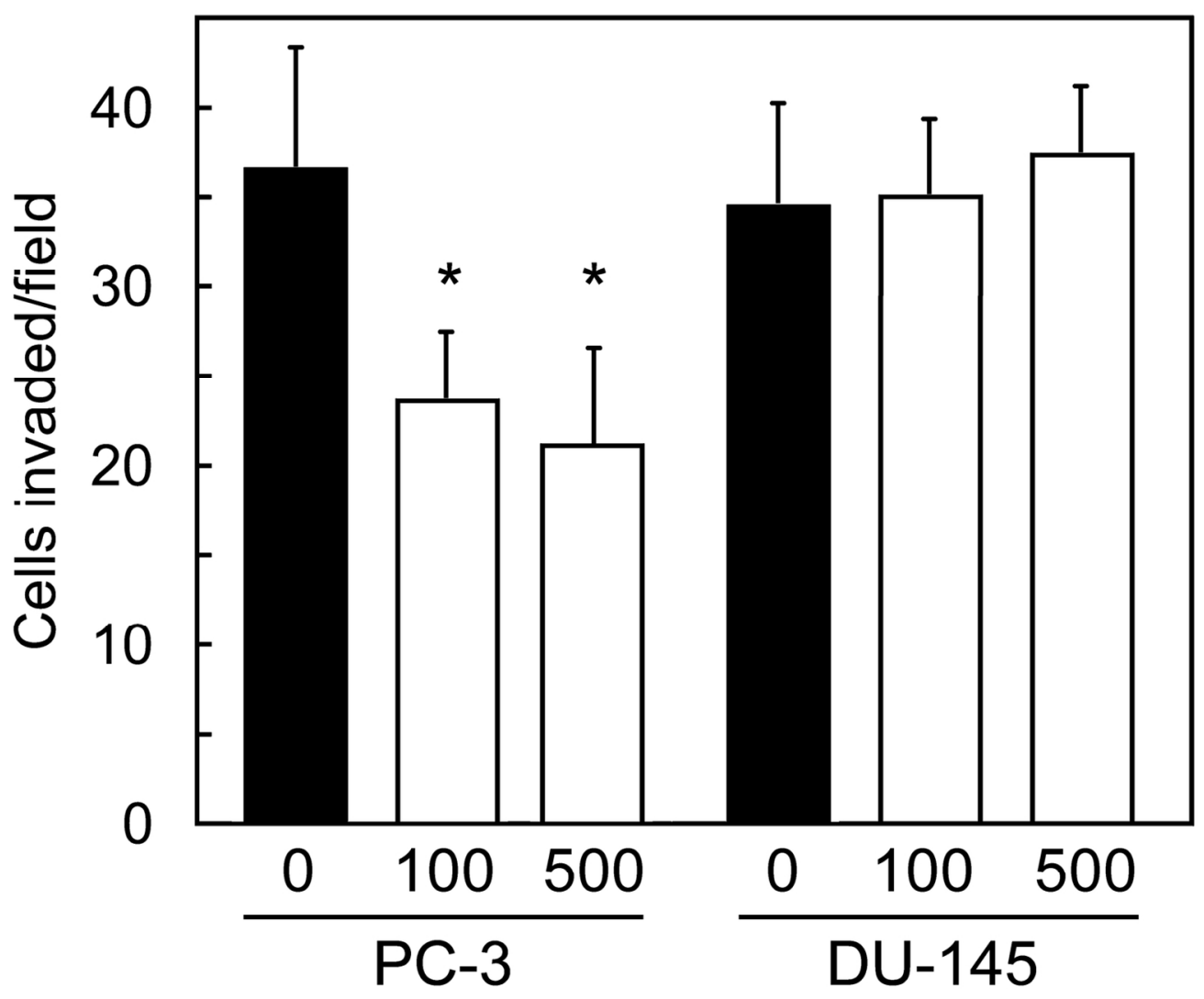

FIGURE 4. Effect of MCoTI-II on cell invasion. Invasion of PC-3 and DU-145 cells through matrigelcoated semi-permeable membranes, in response to $2 \%$ FCS, was determined in the absence (solid bars) and presence of 100 and $500 \mathrm{nM}$ MCoTI-II (open bars, concentrations indicated below) over a 24 hour time period. Data are shown as cell number invaded per microscopic field (mean +/- SEM). Statistical differences between inhibitor-treated and untreated cells were assessed by Student's t-test $(* p<0.05)$. $67 \times 55 \mathrm{~mm}(600 \times 600 \mathrm{DPI})$ 

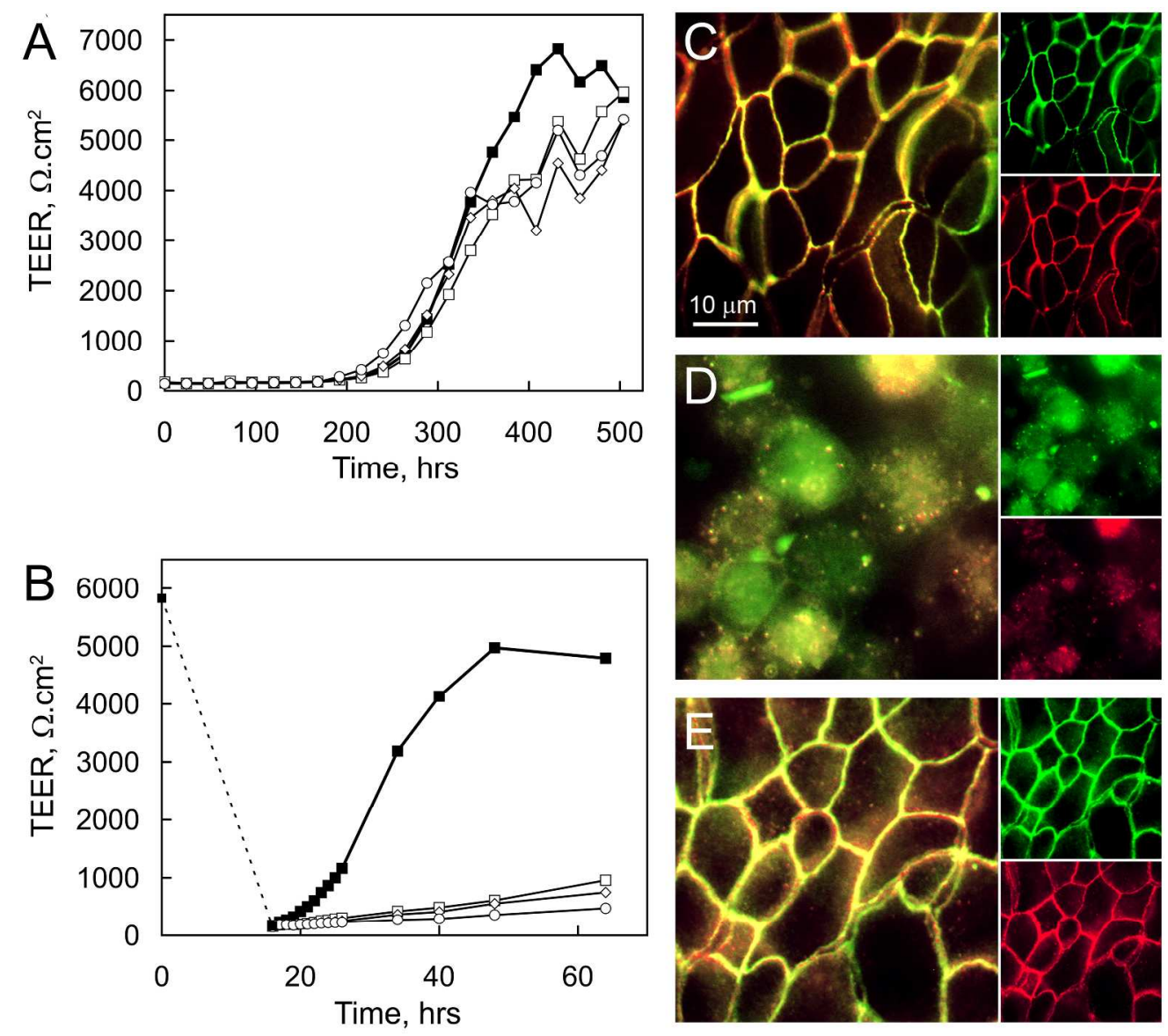

FIGURE 5. MCoTI-II abolishes the reestablishment of tight junctions in MDCK-I cells. (A) MDCK-I cells were grown on Transwell filters in the absence $(\bullet)$ or presence of varying concentrations of MCoTI-II ( $\square$ $250 \mathrm{nM}, \diamond 500 \mathrm{nM}, \circ 1000 \mathrm{nM}$ ) and transepithelial electrical resistance (TEER) measured. (B) MDCK-I cells with high TEER were disrupted by removal of $\mathrm{Ca}^{2+}$ for $16 \mathrm{hrs}$ (dashed line) prior to repletion with $\mathrm{Ca}^{2+}$. MCoTI-II concentrations as in panel A. In all experiments MCoTI-II was included at each change of culture medium. All TEER data shown are means of triplicate determinations. (C-E) Indirect immunofluorescence staining for tight junction proteins in MDCK-I cells grown on Transwell filters as for the TEER experiments.

(C) Prior to $\mathrm{Ca}^{2+}$-switch, (D) after $\mathrm{Ca}^{2+}$-depletion, (E) after $\mathrm{Ca}^{2+}$-repletion for $24 \mathrm{hrs}$. Each panel shows claudin-1 staining (green), ZO-1 staining (red) and co-localization (yellow). Loss of claudin-1 (green) and ZO-1 (red) localisation is apparent during the $\mathrm{Ca}^{2+}$-switch due to disruption of tight junctions, correlating with the changes in TEER shown in panel $B$. $129 \times 116 \mathrm{~mm}(600 \times 600 \mathrm{DPI})$ 
FIGURE 6. Effect of MCoTI-II on activation of prostasin zymogen. HEK-293 cells were transfected with either prostasin alone or cotransfected with both prostasin and matriptase. MCoTI-II (500 nM) was incubated with the cells 6 hours after transfection. Cell lysates were collected at 48 hours post-transfection and subjected to SDS-PAGE and western blot for prostasin. Prostasin zymogen is detected at $41 \mathrm{kDa}$ in the cells transfected with prostasin alone, and the $\mathrm{N}$-terminally truncated activated form is detected at $38 \mathrm{kDa}$ in the cells cotransfected with matriptase. $48 \times 25 \mathrm{~mm}(600 \times 600 \mathrm{DPI})$ 